\title{
Keanekaragaman Jenis Ekhinodermata Di Perairan Minahasa Utara, Sulawesi Utara
}

\author{
Biodiversity of Echinoderm in the North Minahasa Waters, North Sulawesi
}

\author{
Eddy Yusron dan Susetiono
}

Bidang Penelitian Sumberdaya Laut, Puslit Oseanografi - LIPI

Jl. Pasir Putih No. 1, Ancol Timur Jakarta Utara.

E-mail: yusron_01@yahoo.co.id

\begin{abstract}
Observation on echinoderms diversity was carried out at coastal waters of North Minahasa bay, North Sulawesi, from June to August 2008. Sampling was done by using a transect quadrant of $1 \mathrm{~m} \times 1 \mathrm{~m}$. The results showed that in both locations, 28 species of echinoderms represented 7 species of Holothuroidea, 9 species of Echinoidea, 6 species of Asteroidea and 6 species of Ophiuroidea had been found in the North Minahasa Bay, North Sulawesi. The Echinoidea were relatively common in the sea grass zone. On the basis of population density, Echinoidea was the dominant group and had the highest density. This research was aimed to find out the species composition, community structure, zonation, and spatial distribution of echinoderm fauna.
\end{abstract}

Key words: Biodiversity, echinoderm, Minahasa Utara, Sulawesi Utara

\begin{abstract}
Abstrak
Penelitian keanekaragaman ekhinodermata di perairan Minahasa Utara, Sulawesi Utara dilakukan pada bulan Juni dan Agustus 2008. Pengambilan contoh biota dilakukan dengan menggunakan transek kuadrat ukuran $1 \mathrm{~m}$ x $1 \mathrm{~m}$. Dari hasil penelitian didapatkan 28 jenis ekhinodermata yang mewakili 7 jenis Holothuroidea, 9 jenis ekhinoidea, 6 jenis Asteroidea dan 6 jenis Ophiuroidea dari perairan Minahasa Utara, Sulawesi Utara. Kelompok bulu babi (Ekhinoidea) merupakan kelompok yang paling menonjol untuk daerah lamun. Berdasarkan hasil transek yang dilakukan ternyata kelompok bulu babi menempati tingkat kekayaan jenis relatif tinggi. Tujuan penelitian ini untuk melihat komposisi jenis, struktur komunitas, zonasi, dan sebaran lokal.
\end{abstract}

Kata kunci: Keanekaragaman, ekhinodermata, Minahasa Utara, Sulawesi Utara

Diterima: 27 April 2009, disetujui: 05 Mei 2010

\section{Pendahuluan}

Perairan Minahasa Utara yang masuk
dalam wilayah Propinsi Sulawesi Utara
merupakan perairan yang dikenal mempunyai
keanekaragaman jenis invertebrata terutama dari
kelompok Ekhinodermata. Wilayah perairan
pantai Minahasa Utara ditumbuhi oleh jenis
lamun (seagrass), rumput laut (seaweed) dan
terumbu karang.
Lamun telah dikenal berperan penting
pada ekosistem pantai, antara lain : sebagai
tempat mencari makan dan persinggahan bagi
berbagai tumbuhan serta hewan; memperkaya
produksi primer di perairan pantai; menangkap

dan mendaur ulang nutrien dan sebagai stabilisator sedimen dan garis pantai (Kawaroe et al., 2010). Di samping itu, padang lamun berperan sangat penting sebagai tempat asuhan dan habitat bagi beberapa jenis ikan dan invertebrata (Nienhuis, 1993), sedangkan ekosistem terumbu karang merupakan habitat dari berbagai jenis biota laut. Salah satunya dari kelompok ekhinodermata (Birkeland, 1989). Ekhinodermata ini dapat hidup menempati berbagai macam habitat seperti zona rataan terumbu, daerah pertumbuhan algae, padang lamun, koloni karang hidup dan karang mati dan beting karang (rubbles dan boulders). Kehadiran dan peranan kelompok ekhinodermata di ekosistem terumbu karang ini telah dilaporkan 
oleh Birkeland, 1989. Beberapa studi lainnya mengenai penelitian aspek ekologi ekhinodermata di perairan Indonesia telah banyak ditulis (Yusron, 2003 dan Toha, 2007).

Kelompok Ekhinodermata mempunyai peranan penting pada jaringan makanan pada ekosistem terumbu karang, sebagai herbivora, carnivora, omnivora ataupun sebagai pemakan detritus (Best, 1994 dan Toha, 2007). Selain itu, kelompok ekhinodermata juga sebagai sumber makanan bagi biota yang hidup di ekosistem terumbu karang. Salah satu contoh jenis teripang dan bulu babi merupakan sumber pakan untuk berbagai jenis ikan karang (Birkeland, 1989). Informasi mengenai kehadiran kelompok ekhinodermata di perairan Minahasa Utara, Sulawesi Utara belum banyak yang ditulis. Tulisan ini merupakan hasil dari proyek penelitian Biodiversitas di perairan Minahasa Utara, Sulawesi Utara tahun 2008, Semoga tulisan ini dapat memberikan informasi biota laut dari perairan Indonesia.

\section{Metode Penelitian}

Penelitian dilakukan di perairan Minahasa Utara, Sulawesi Utara pada tanggal 16-20 Juni 2008 dan 21-26 Agustus 2008 pada posisi geografi $1^{0} 36^{\prime} 28^{\prime \prime}-1^{0} 45^{\prime} 35^{\prime \prime} \mathrm{LU}$ dan antara $124^{0} 45^{\prime} 35^{\prime \prime}-124^{0} 54^{\prime} 42^{\prime \prime}$ BT, Lokasi penelitian yaitu: Lansa, Buhias dan Nain (Gambar 1).

Pengambilan contoh ekhinodermata pada setiap lokasi dilakukan 2 kali transek dengan jarak transek 50 meter menggunakan "metode transek kuadrat". Tali transek ditarik tegak lurus dari posisi titik surut terendah ke arah laut sepanjang 100 meter, dengan plot pengamatan dari frame kerangka pralon berukuran $1 \mathrm{~m}$ x $1 \mathrm{~m}$. Titik plot pengamatan dilakukan setiap jarak 10 meter sepanjang garis transek. Pengamatan dilakukan saat air menjelang surut pada siang hari. Setiap ekhinodermata yang terdapat dalam kerangka frame tersebut dicatat jumlah jenis dan jumlah individunya. Selain itu juga dicatat substrat untuk memberikan zonasi dari sebaran lokal fauna tersebut. Untuk melengkapi data kuantitatif ini juga dilakukan koleksi bebas dan pengamatan secara visual untuk memberikan gambaran mengenai sebaran lokal dan kekayaam jenis ekhinodermata.
Identifikasi jenis ekhinodermata dilakukan dengan bantuan kepustakaan Allen dan Steene, (1999); Clark dan Rowe, (1971); Rowe, (1969); Rowe dan Doty, (1977); Colin dan Arneson, (1995); Gosliner et al., (1996). Untuk menghitung beberapa karakter komunitas yaitu, kekayaan jenis dan keanekaragaman jenis ekhinodermata dapat ditelaah dengan menggunakan aplikasi program "Comm" (Gross, 1992) indeks Margalef (D), keragaman Pielou (J) dan kemerataan Shannon $(\mathrm{H})$ sebagai berikut :

$$
\begin{aligned}
& \text { Indeks Margalef }(D)=\frac{\mathrm{S}-1}{\log \mathrm{N}} \\
& \text { Indeks Shannon-Wiener }(\mathrm{H})=-\Sigma(\mathrm{ni} / \mathrm{N}) \ln (\mathrm{ni} / \mathrm{N}) \\
& \text { Indeks Pielou }(\mathrm{J})=\frac{\mathrm{H}}{\log \mathrm{S}}
\end{aligned}
$$

Dimana: $\mathrm{S}=$ Jumlah total jenis

$\mathrm{N}=$ Jumlah total individu yang diamat $\mathrm{ni}=$ Jumlah individu jenis ke I

\section{Hasil dan Pembahasan}

Lokasi Langsa mempunyai substrat pasir halus dan relatif sama dengan Buhias dan Nain, yaitu dimulai dengan zona pasir, diikuti oleh zona pertumbuhan lamun, terumbu karang dan pohon bakau. Pada ketiga lokasi tersebut didapatkan banyak ditumbuhi berbagai jenis lamun diantaranya jenis Enhalus acoroides, Cymmodocea rotundata, Thalassia hemprichii, Cymodocea serrulata, Syringodium isoetifolium, Halophila ovalis, Halodule pinifolia dan Halodule uninervis. Di lokasi Langsa dan Nain didapatkan bebarapa jenis rumput laut diantaranya jenis Gracilaria lichenoides, Hypnea servicornis, Eucheuma spinosum dan Sargassum crispyfolium.

Dari hasil pengamatan ekhinodermata di tiga lokasi didapatkan 4 kelas yaitu holothuroidea, ekhinoidea, asteroidea dan ophiuroidea. Kelas crinoidea tidak ditemukan. Hal ini disebabkan kelas crinoidea biasanya hidup di daerah tubir sehingga sulit untuk dikoleksi.

Selama pengamatan di tiga lokasi penelitian ditemukan 28 jenis ekhinodermata yang termasuk dalam 4 kelas (Tabel 1 dan 2). 
Kelas Holothuroidea (teripang) terdapat 7 jenis, kelas Ekhinoidea (bulu babi) ada 9 jenis, kelas Asteroidea (bintang laut) ada 6 jenis dan kelas Ophiuroidea (bintang mengular) ada 6 jenis. Kelompok yang paling tinggi kehadirannya dalam pengamatan ini adalah bulu babi (ekhinoidea), dari jenis Mespelia globulus dan Tripneustes gratilla yang ditemukan melimpah pada lokasi yang banyak ditumbuhi lamun, terutama pada lokasi Langsa dan Nain.

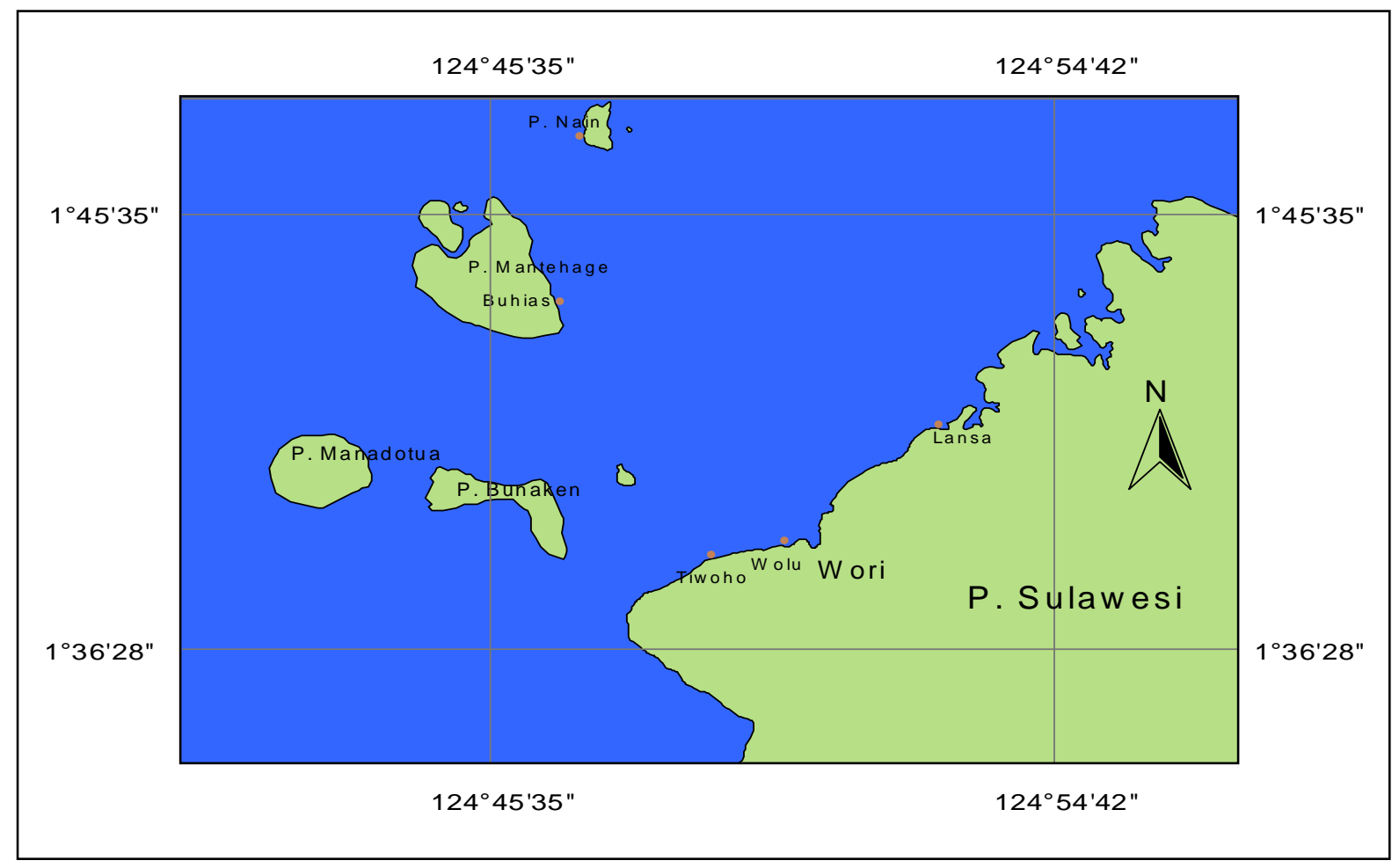

Gambar 1. Lokasi Penelitian Ekhinodermata di Perairan Minahasa Utara, Sulut

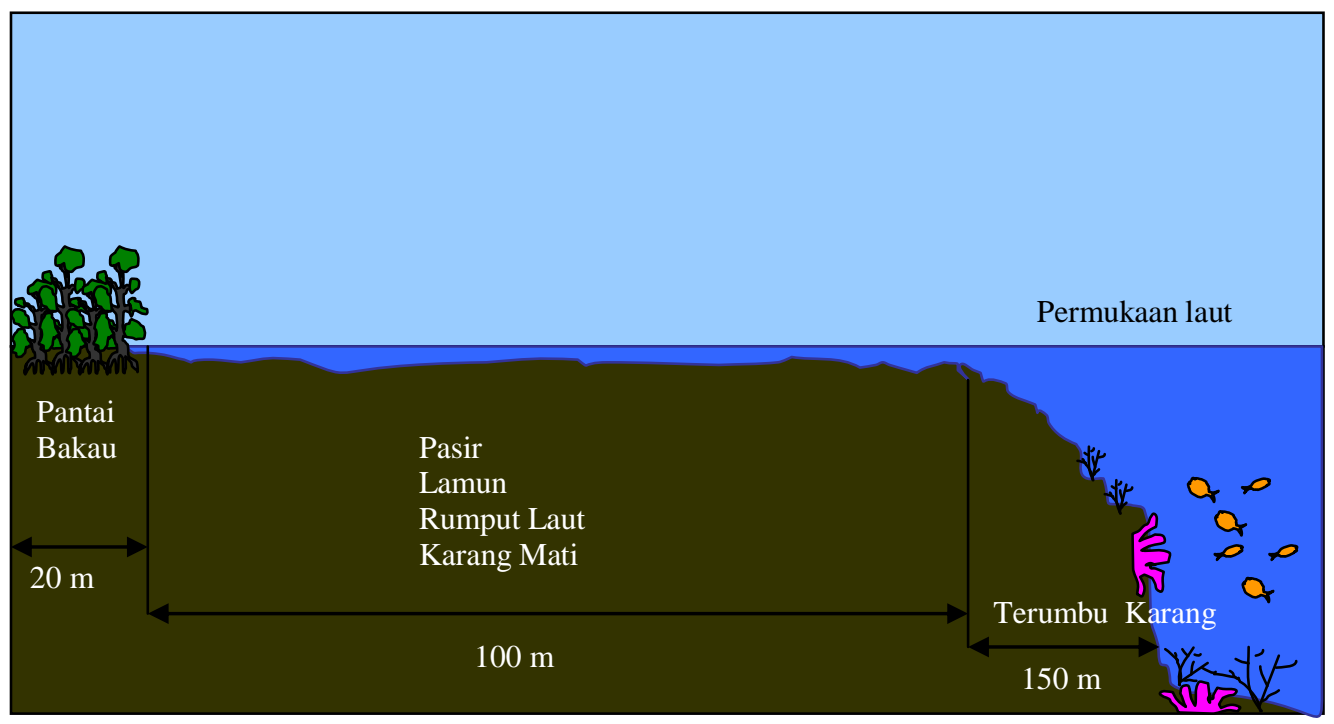

Gambar 2. Profil pantai pada ketiga lokasi penelitian 
Hasil penelitian ini dibandingkan dengan jenis ekhinodermata di perairan daerah terumbu karang Pulau-pulau Derawan, Kalimatan Timur, maka tingkat kekayaan jenis ekhinodermata di perairan Minahasa Utara, Sulawesi Utara lebih kecil, terutama dalam jumlah jenis dan individu. Di perairan terumbu karang Pulau-pulau Derawan, Kalimatan Timur didapatkan 52 jenis fauna Ekhinodermata (Darsono dan Aziz, 2001), sedang pada penelitian ini hanya ditemukan 28 jenis ekhinodermata. Dari hasil perhitungan pada setiap lokasi penelitian mempunyai jumlah jenis antara 12-24 jenis, dan jumlah individu antara 41-89, sedangkan untuk melihat pada setiap lokasi pengamatan dapat dilihat pada Tabel 1 .

Tabel 1. Jenis ekhinodermata dari transek di perairan Minahasa Utara, Sulawesi Utara.

\begin{tabular}{|c|c|c|c|c|c|c|c|}
\hline \multirow{3}{*}{ No } & \multirow{3}{*}{ Kelas/jenis } & \multicolumn{6}{|c|}{ Loka s i } \\
\hline & & \multicolumn{2}{|c|}{ Lansa } & \multicolumn{2}{|c|}{ Buhias } & \multicolumn{2}{|c|}{ Nain } \\
\hline & & 1 & 2 & 1 & 2 & 1 & 2 \\
\hline $\bar{I}$ & Holothuroidea & & & & & & \\
\hline 1 & Holothuria atra & 1 & 2 & 1 & 0 & 2 & 0 \\
\hline 2 & Holothuria hilla & 1 & 2 & 1 & 3 & 1 & 1 \\
\hline 3 & Holothuria leucospilota & 0 & 2 & 1 & 0 & 0 & 0 \\
\hline 4 & Holothuria scabra & 2 & 1 & 0 & 0 & 0 & 0 \\
\hline 5 & Bochadschia argus & 1 & 2 & 0 & 0 & 0 & 0 \\
\hline 6 & Synapta maculata & 3 & 2 & 1 & 2 & 0 & 0 \\
\hline 7 & Euapta godeffroyi & 1 & 2 & 0 & 0 & 2 & 1 \\
\hline II & Echinoidea & & & & & & \\
\hline 8 & Astropyga radiata & 0 & 2 & 0 & 0 & 0 & 0 \\
\hline 9 & Diadema setosum & 6 & 12 & 8 & 11 & 4 & 9 \\
\hline 10 & Diadema savignyi & 3 & 5 & 3 & 2 & 2 & 1 \\
\hline 11 & Mespilia globulus & 12 & 8 & 4 & 6 & 0 & 0 \\
\hline 12 & Tripneustes gratilla & 20 & 22 & 8 & 12 & 4 & 6 \\
\hline 13 & Echinothrix calamaris & 1 & 2 & 0 & 0 & 0 & 0 \\
\hline 14 & Echinometra mathaei & 0 & 0 & 4 & 7 & 4 & 3 \\
\hline 15 & Pseudoboletia maculata & 2 & 1 & 0 & 0 & 0 & 0 \\
\hline 16 & Brissus latercarinatus & 2 & 3 & 1 & 2 & 0 & 0 \\
\hline III & Asteroidea & & & & & & \\
\hline 17 & Linckia laevigata & 2 & 4 & 2 & 1 & 0 & 0 \\
\hline 18 & Nardoa tuberculata & 0 & 0 & 2 & 0 & 0 & 0 \\
\hline 19 & Culcita novaeguineae & 2 & 1 & 1 & 0 & 0 & 0 \\
\hline 20 & Protoreaster nodosus & 4 & 2 & 0 & 1 & 1 & 2 \\
\hline 21 & Echinaster luzonicus & 0 & 1 & 0 & 0 & 0 & 0 \\
\hline 22 & Archaster typicus & 2 & 0 & 0 & 0 & 2 & 5 \\
\hline IV & Ophiuroidea & & & & & & \\
\hline 23 & Ophiocoma erinaceus & 1 & 1 & 2 & 1 & 0 & 0 \\
\hline 24 & Ophiothrix hybrida & 1 & 3 & 0 & 0 & 0 & 2 \\
\hline 25 & Ophioarthrum pictum & 5 & 4 & 8 & 5 & 12 & 8 \\
\hline 26 & Ophiarthrum elegans & 2 & 1 & 2 & 4 & 1 & 2 \\
\hline 27 & Ophiarachna incrassata & 0 & 0 & 6 & 3 & 0 & 0 \\
\hline 28 & Ophiomastix variabilis & 8 & 4 & 8 & 12 & 6 & 7 \\
\hline \multicolumn{2}{|c|}{ Jumlah Jenis } & 22 & 24 & 18 & 15 & 12 & 12 \\
\hline \multicolumn{2}{|c|}{ Jumlah Individu } & 82 & 89 & 63 & 72 & 41 & 47 \\
\hline \multicolumn{2}{|c|}{ Indeks Diversitas (H) } & 1,342 & 1,380 & 1,255 & 1,176 & 1,079 & $\mathbf{1 , 0 7 9}$ \\
\hline \multicolumn{2}{|c|}{ Indeks Kemerataan (J) } & 0,846 & $\mathbf{0 , 8 5 3}$ & 0,900 & $\mathbf{0 , 8 8 8}$ & $\mathbf{0 , 8 7 9}$ & $\mathbf{0 , 8 9 6}$ \\
\hline \multicolumn{2}{|c|}{ Indeks Kekayaan Jenis (D) } & 10,125 & 10,641 & 13,377 & 10,306 & 7,961 & 9,319 \\
\hline
\end{tabular}


Berdasarkan analisa kuantitatif diperoleh suatu gambaran bahwa nilai indeks diversitas (indeks Shannon) tertinggi ditemukan pada lokasi Pantai Lansa pada transek $1\left(\mathrm{H}^{\prime}=1,380\right)$, dan nilai indeks kemerataan tertinggi (nilai Pielou) terdapat pada lokasi Buhias pada transek $1(\mathrm{~J}=0,900)$, sedangkan nilai indeks kekayaan jenis (indeks Margalef) tertinggi didapatkan pada lokasi Buhias pada transek $1(\mathrm{D}=13,337)$. Dari hasil penelitian di perairan daerah terumbu karang di Pulau-pulau Muna, Sulawesi Tenggara masing mempunyai nilai indeks diversitas $\left(\mathrm{H}^{\prime}=\right.$ $1,189)$, indeks kemerataan $(\mathrm{J}=0,911)$ dan indeks kekayaan jenis ( $\mathrm{D}=2,674)$ (Yusron, 2003). Adapun hasil penelitian di perairan Teluk Lampung, Sumatera pada 5 lokasi mempunyai nilai indeks diversitas $\left(\mathrm{H}^{\prime}=2,450\right)$, indeks kemerataan $(\mathrm{J}=0,973)$ dan indeks kekayaan jenis $(\mathrm{D}=3,219)$ (Darsono dan Aziz, 2001). Dari nilai indeks diversitas, indeks kemerataan dan indeks kekayaan jenis yang didapatkan di perairan Minahasa Utara lebih rendah dibanding dilokasi Muna, Teluk Lampung.

Kelompok Ekhinodermata adalah merupakan salah satu komponen penting dalam hal keanekaragaman fauna di daerah terumbu karang (Clark, 1976 dan Bakus, 1973). Hal ini karena terumbu karang berperan sebagai tempat berlindung dan sumber pakan bagi jenis ekhinodermata. Secara ekologis ekhinodermata berperan sangat penting dalam ekosistem terumbu karang, terutama dalam rantai makanan (food web), karena biota tersebut umumnya sebagai pemakan detritus dan predator (Birkeland, 1989). Salah satu contoh jenis asteroid umumnya sebagai fauna predator, yaitu jenis Acanthaster planci sebagai pemangsa polip karang, sedangkan jenis ophiuroid dan holothuroid adalah sebagai pemakan detritus, dan beberapa jenis echinoid sebagai herbivora (Toha, 2007).

Sebaran relatif jenis terhadap dasar perairan disajikan pada Tabel 2. Ekhinodermata paling banyak ditemukan pada habitat lamun (21 jenis), diikuti oleh habitat rumput laut (13 jenis), 8 jenis menempati mikrohabitat karang mati dan 10 jenis menempati mikrohabitat pasir. Nilai varian, rata-rata dan penyebaran dapat dilihat Tabel 3. Dari hasil analisis Nilai varian, ratarata, probalitas dan penyebaran jenis-jenis ekhinodermata di perairan Minahasa Utara, Sulawesi Utara mempunyai pola penyebaran acak, kecuali 4 jenis yang mempunyai penyebaran merata di mana setiap lokasi tarnsek ditemukan ke empat jenis tersebut yaitu: Mespilia globules, Tripneustes gratilla, Archaster typicus dan Ophiomastix variabilis.

Tabel 2. Penyebaran Ekhinodermata berdasarkan mikrohabitat di perairan Minahasa Utara, Sulawesi Utara.

\begin{tabular}{|c|c|c|c|c|c|}
\hline No & Kelas / Jenis & Pasir & Lamun & "Rumput Laut & Karang Mati \\
\hline 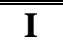 & "Holothuroidea & & & & \\
\hline 1 & Holothuria atra & - & + & - & - \\
\hline 2 & Holothuria hilla & - & + & - & - \\
\hline 3 & Holothuria leucospilota & - & - & + & + \\
\hline 4 & Holothuria scabra & + & + & - & - \\
\hline 5 & Bochadschia graffei & - & + & + & - \\
\hline 6 & Synapta maculata & - & + & - & - \\
\hline 7 & Euapta godeffroyi & - & + & - & - \\
\hline II & Echinoidea & & & & \\
\hline 8 & Astropyga radiata & + & + & + & - \\
\hline 9 & Diadema setosum & - & + & + & + \\
\hline 10 & Diadema savignyi & - & + & + & - \\
\hline 11 & Mespilia globulus & + & + & + & - \\
\hline 12 & Tripneutes gratilla & + & + & + & - \\
\hline 13 & Echinothrix calamaris & - & + & - & + \\
\hline 14 & Echinometra mathaei & + & - & - & + \\
\hline 15 & Pseudoboletia maculata & - & + & - & - \\
\hline 16 & Brissus latercarinatus & + & - & - & - \\
\hline III & Asteroidea & & & & \\
\hline 17 & Linckia laevigata & + & + & - & - \\
\hline 18 & Nardoa tuberculata & - & - & - & + \\
\hline
\end{tabular}


Tabel 2. Lanjutan

\begin{tabular}{clcccc}
\hline \hline No & \multicolumn{1}{c}{ Kelas / Jenis } & Pasir & Lamun & Rumput Laut & Karang Mati \\
\hline \hline 19 & Culcita novaeguineae & - & - & - & - \\
20 & Protoreaster nodosus & - & + & - & - \\
21 & Echinaster luzonicus & - & + & + & + \\
22 & Archaster typicus & + & +- & + & \\
IV & Ophiuroidea & & & & \\
23 & Ophiocoma erinaceus & & & & + \\
24 & Ophiothrix hybrida & - & + & + & - \\
25 & Ophioarthrum pictum & - & + & + & + \\
26 & Ophiarthrum elegans & - & + & + & - \\
27 & Ophiarachna incrassata & + & + & + & \\
28 & Ophiomastix variabilis & & & & \\
\hline \hline
\end{tabular}

Keterangan : + = Dijumpai - = Tidak dijumpai

Tabel 3. Nilai varian, rata-rata, probalitas dan penyebaran jenis-jenis ekhinodermata di perairan Minahasa Utara, Sulawesi Utara.

\begin{tabular}{|c|c|c|c|c|c|c|}
\hline No & Kelas / Jenis & Varian & Rata-rata & $\sum \mathbf{X}^{2}$ & Probabilitas & Penyebaran \\
\hline I I & Holothuroidea & & & & & \\
\hline 1 & Holothuria atra & 0,800 & 1,000 & 4,000 & 0,5514 & Acak \\
\hline 2 & Holothuria hilla & 0,700 & 1,500 & 2,333 & 0,8033 & Acak \\
\hline 3 & Holothuria leucospilota & 0,700 & 0,500 & 7,000 & 0,2195 & Acak \\
\hline 4 & Holothuria scabra & 0,700 & 0,500 & 7,000 & 0,2195 & Acak \\
\hline 5 & Bochadschia graffei & 0,700 & 0,500 & 7,000 & 0,2195 & Acak \\
\hline 6 & Synapta maculata & 1,466 & 1,333 & 5,500 & 0,3579 & Acak \\
\hline 7 & Euapta godeffroyi & 0,800 & 1,000 & 4,000 & 0,5514 & Acak \\
\hline II & Echinoidea & & & & & \\
\hline 8 & Astropyga radiata & 0,667 & 0,333 & 10,000 & 0,0744 & Acak \\
\hline 9 & Diadema setosum & 9,067 & 8,333 & 5,440 & 0,3646 & Acak \\
\hline 10 & Diadema savignyi & 1,867 & 2,667 & 3,500 & 0,6258 & Acak \\
\hline 11 & Mespilia globulus & 22,000 & 5,000 & 22,000 & 0,0006 & Merata \\
\hline 12 & Tripneutes gratilla & 56,000 & 12,000 & 23,333 & 0,0003 & Merata \\
\hline 13 & Echinothrix calamaris & 0,700 & 0,500 & 7,000 & 0,2195 & Acak \\
\hline 14 & Echinometra mathaei & 7,200 & 3,000 & 12,000 & 0,0345 & Acak \\
\hline 15 & Pseudoboletia maculata & 0,700 & 0,500 & 7,000 & 0,2195 & Acak \\
\hline 16 & Brissus latercarinatus & 1,467 & 1,333 & 5,500 & 0,3579 & Acak \\
\hline III & Asteroidea & & & & & \\
\hline 17 & Linckia laevigata & 2,300 & 1,500 & 7,666 & 0,1743 & Acak \\
\hline 18 & Nardoa tuberculata & 0,667 & 0,333 & 10,000 & 0,0744 & Acak \\
\hline 19 & Culcita novaeguineae & 0,667 & 0,667 & 5,000 & 0,4165 & Acak \\
\hline 20 & Protoreaster nodosus & 1,867 & 1,667 & 5,600 & 0,3469 & Acak \\
\hline 21 & Echinaster luzonicus & 0,166 & 0,166 & 5,000 & 0,4165 & Acak \\
\hline 22 & Archaster typicus & 3,900 & 1,500 & 13,000 & 0,0032 & Merata \\
\hline IV & Ophiuroidea & & & & & \\
\hline 23 & Ophiocoma erinaceus & 0,566 & 0,830 & 3,400 & 0,6441 & Acak \\
\hline 24 & Ophiothrix hybrida & 1,600 & 1,000 & 8,000 & 0,1549 & Acak \\
\hline 25 & Ophioarthrum pictum & 8,800 & 7,000 & 6,285 & 0,2786 & Acak \\
\hline 26 & Ophiarthrum elegans & 1,200 & 2,000 & 3,000 & 0,7025 & Acak \\
\hline 27 & Ophiarachna incrassata & 6,300 & 1,500 & 21,000 & 0,0019 & Merata \\
\hline 28 & Ophiomastix variabilis & 7,100 & 7,500 & 4,733 & 0,5497 & Acak \\
\hline
\end{tabular}




\section{Simpulan dan Saran}

\section{Simpulan}

Berdasarkan hasil pengamatan di tiga lokasi ditemukan 28 jenis fauna ekhinodermata yang termasuk dalam 4 kelas yaitu kelas Holothuroidea (teripang) diwakili 7 jenis, kelas Echinoidea (bulu babi) diwakili oleh 9 jenis, kelas Asteroidea (bintang laut) diwakili oleh 6 jenis dan kelas Ophiuroidea (bintang mengular) diwakili 6 jenis. Biota Jenis-jenis ekhinodermata di perairan Minahasa Utara mempunyai pola penyebaran cenderung acak.

\section{Saran}

Perlu menjaga kelestarian lingkungan wilayah pesisir dari kerusakan akibat oleh perbuatan manusia dan melakukan penelitian yang lebih mendalam mengenai kajian hubungan antara faktor kondisi lingkungan dan jenis ekhinodermatanya di perairan tersebut.

\section{Ucapan Terima Kasih}

Ucapan terima kasih kami sampaikan pada saudara Mohtar Djabar, Dahlan Mantiri dan Ade Saputra yang telah membantu hingga penelitian ini selesai.

\section{Daftar Pustaka}

Alen, G.R. dan Steene, R. 1999. Indo-Pacific coral reef field guide. Tropical Reef Research. 378 Pp.

Birkeland, C. 1989. The Influence of Echinoderm on Coral Reef Communities. In: Echinoderms, S.M.J. and Lawrence, J.M. (Eds.). vol. 3. A.A. Balkema, Rotterdam, Netherland: 79 pp.

Bakus, G.J. 1973. The Biology and Ecology of tropical holothurian, In: Jones, O.A. and Endean, R. (Eds.). Biology and Geology of Coral Reef, Vol 2, Academic Press, New York.

Best, M.B. 1994. Biodiversity of the Coral Reefs of SouthWest Sulawesi. Torani spec, 5: 22-29.
Clark, A.M. 1976. Echinoderm of Coral Reefs, In: Jones, O.A. and Endean (Eds.) Geology and Ecology of Coral Reefs. 3. Acad. Press, New York: 95-123.

Clark, A.M. dan Rowe, F.W.E. 1971. Monograph of Shallow-water Indo West Pasific Echinoderms. Trustees of the British Museum (Natural History). London: 238 pp.

Colin, P.L. dan Arneson, C. 1995. Tropical Pacific Invertebrates. The Coral Reef Research Foundation. CA, USA. 296 pp.

Darsono, P. dan Aziz, A. 2001. Fauna Ekhinodermata dari Beberapa Pulau di Teluk Lampung. In: Aziz, A., and Muchtar, M. (Eds.). Dalam Perairan Indonesia: Oseanografi, Biologi dan Lingkungan Pusat Penelitian dan Pengembangan Oseanologi LIPI. Jakarta: 103-120.

Gross, O. 1992. A Manual for use of the COMM Program Prepared for. Dr.D. Ellis. University of Victoria, B.C. Canada. 52 pp (unpublished).

Gosliner, T.M., Behrens, D.W. dan Williams, G.C. 1996. Coral Reef Animals of the Indo-Pasific. Sea Challengers, C.A. 314 pp.

Kawaroe, M., Indra, J., Indarto, H.S., Dahlia, W.S. dan Sundari, W.W. 2010. Perubahan Luas Penutupan Padang Lamun Di Kepulauan Seribu, DKI Jakarta. Biota, 15 (1): 17-23.

Nienhuis, P. 1993. Structure and Functioning of Indoensian Seagrass Ecosystem, In: Moosa, M.K., De Iongh, H.H., Blauw, H.J.A. and Morimarna, M.K.J. (Eds). Proceeding International Seminar on Coastal Zone Management of Small Island Ecosystem, Ambon, Indonesia.

Rowe, F.W.E. 1969. A Review of Family Holothuroidae (Holothuroidae $=$ Aspidochirotida). Bull. $\mathrm{Br}$. Mus. Nat. His. Zool. 117-170.

Rowe, F.W.E. dan Doty, J.E. 1977. The Shallow - water Holothurian of Guam. Micronesica, 13 (2): 217-250.

Toha, A.H.A. 2007. Keragaman Genetik Bulu Babi (Echinoidea). Biota, 12 (2): 131-135.

Yusron, E. 2003. Fauna Ekhinodermata di Daerah Terumbu Karang di Pulau-pulau Muna, Sulawesi Tenggara. Dalam Pesisir dan Pantai Indonesia VIII. Pusat Penelitian Oseanografi-LIPI. Jakarta. 